\title{
Spondylodiscitis and ankylosing spondylitis: HLA typing and nosological implications
}

\author{
V. MODENA*, N. MIGONE†, V. DANEO*, A. O. CARBONARA $\dagger$, \\ S. DI VITTORIO + , AND M. VIARA**
}

SUMMARY Nine cases from among 64 patients with ankylosing spondylitis (AS) are described. In addition to bilateral sacroiliitis these cases had a peculiar type of spondylodiscitis characterised by quite diffuse and marked sclerosis of multiple vertebral bodies, with only minimal erosions Ff the adjacent vertebral plates while classical syndesmophytosis was absent. The antigen HLA-B2.7 was found only in 1 of these 9 cases. This type of spondylodiscitis could discriminate among \ौ the patients with AS a subgroup with a peculiar clinical pattern and a probably distinctive patkological mechanism.

Erosive sclerotic lesions of the vertebral bodies surrounding a disc-spondylodiscitis (SD) - have been reported in between 1 and $28 \%$ of patients suffering from ankylosing spondylitis (AS) (Forestier et al., 1956; Jaqueline, 1956; Schulitz, 1969; Daneo and Di Vittorio, 1970; Cawley et al., 1972; Doury et al., 1975). Different methods in selecting the patients, different extent of spinal survey, and lack of agreed diagnostic criteria for spondylodiscitis may account for this wide variation in prevalence.

There is no agreement about the origin of these lesions, some authors favouring traumatic (Kanefield et al., 1969; Rivelis and Freiberger, 1969; Cawley et al., 1972; Gougeon et al., 1977), others inflammatory mechanisms (Romanus and Ydén 1952; Coste et al., 1963; Little et al., 1974). In the most destructive lesions, often occurring in the late stages of AS at only one vertebral metamer, namely at the hinge-point between two ankylosed spinal segments, the traumatic mechanism is likely.

A peculiar feature of a different SD in subjects diagnosed as having AS was discussed by Daneo and Di Vittorio (1970). This type is characterised by quite diffuse and marked sclerosis of multiple vertebral bodies with only minimal erosions of the

Accepted for publication February 15, 1978

This work has been partly supported by the CNR, Centro di Studio per l'Immunogenetica e l'Istocompatibilità, Torino, Italy.

* Centro di Reumatologia, Ospedale San Giovanni, Torino, Italy.

† Istituto di Genetica Medica dell'Università, Torino, Italy. ¥ Ospedale S. Andrea, Vercelli, Italy.

** Istituti Ospedalieri S. Corona, Pietra Ligure, Savona, Italy.

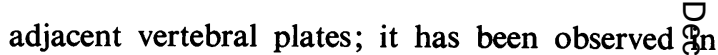
patients with bilateral definite sacroiliitis and symptoms or signs referred to the spine, in absence कू f clear syndesmophytosis.

The HLA typing of patients affected byô $\overrightarrow{A S}$ complicated by this latter feature of spondylogd\$scitis is reported in the present study. The lowo frequency of the B27 antigen together with pecutlin clinical and radiological findings are discussed.

\section{Patients and methods}

From a series of 64 patients fulfilling the diagnostic criteria for AS (Gofton, 1968) 9 subjects (14\%) had radiological signs of SD. These 9 patients, together with their available first-degree relatives $(>16$ yeabss of age) - 2 parents, 3 sibs, and 3 children - underwent clinical and radiological investigation. Information on the health status of other 38 first-degree relatives was also collected by means of a direct intervien with the proband. A total of 17 subjects were typed for HLA-A, B, C specificities as described previousy (Daneo et al., 1977). A panel of 1428 healthy indi viduals constituted the control for HLA antige frequency.

\section{Results}

All the 9 patients were males, with a mean age $\overline{\text { fif }}$ $39 \cdot 2 \pm 11 \cdot 3$ years (Table). The first clinical symetom appeared at a mean age of $21 \cdot 7 \pm 5 \cdot 5$ yeapss and was represented by persistent lumbar paifi, followed later by gluteal complaints. The pelvie $x$-rays showed severe bilateral sacroiliitis (grade $3 \frac{9}{8}$, 
Table Main clinical, radiological, and HLA data of 64 AS patients, according to the presence or absence of spondylodiscitis $(S D)$

\begin{tabular}{lll}
\hline & \multicolumn{2}{l}{ Ankylosing spondylitis } \\
\cline { 2 - 3 } & With $S D(n=9)$ & Without $S D(\mathrm{n}=55)$ \\
\hline Mean age & $39 \cdot 2 \pm 11 \cdot 3$ & $40 \cdot 2 \pm 12$ \\
Sex (males/females) & $9 / 0$ & $52 / 3$ \\
Initial complaint & Lumbar & Gluteal \\
Mean age at onset & $21 \cdot 7 \pm 5 \cdot 5$ & $26 \cdot 9 \pm 8 \cdot 5 *$ \\
Bilateral sacroilitis & $9(100 \%)$ & $55(100 \%)$ \\
Syndesmophytosis & $1(11 \cdot 1 \%)$ & $47(85 \cdot 4 \%) \dagger$ \\
B27 antigen positivity & $1(11 \cdot 1 \%)$ & $48(87 \cdot 3 \%) \ddagger$ \\
\hline
\end{tabular}

*P=0.08 (Student's $t$ test).

$\dagger P=5^{-5}$ (Fisher's exact test).

$\ddagger P=2^{-5}$ (Fisher's exact test).

according to Gofton (1968)) in all 9 cases. The spondylodiscitic lesions were characterised by diffuse and marked sclerosis of vertebral bodies, with minimal erosions of the adjacent vertebral plates (Fig.). The findings were at 3 or more levels in 5 cases, at 2 levels in 3 cases and at 1 level in 1. However, the absence of classical features of syndesmophytosis, except 1 case (B27-negative) is worth noting. In this patient the process was confined to one vertebral body and to an initial stage. Moreover voluminous intervertebral bony bridges recalling the osteophytic and not the syndesmophytic-like pattern were documented in 2 subjects aged 33 and 41, respectively.

The HLA typing showed that 8 out of 9 were B27negative and only 1 B27-positive. No other HLA specificities were significantly different when compared with the antigen frequencies of the control population. Nevertheless, out of 9 cases 6 carried the HLA-A2 and 4 the HLA-B5 antigen.

Preliminary family analysis showed only 2 affected firts-degree relatives; 2 brothers with sacroiliitis in the family of the B27-positive proband.

\section{Discussion}

Spondylodiscitic lesions have been documented in patients affected by AS. Some authors suggest that these vertebral involvements could be a possible late complication of classical AS, following a known or suspected trauma upon an ankylosed spine. Others think that these unusual signs might be related to the same inflammatory mechanism of the primary disease.

Recently, Daneo and Di Vittorio (1970) and Little et al. (1974) have stressed the precocious occurrence in some AS patients of primary spondylodiscitic lesions at multiple levels, in the absence of classical spinal syndesmophytosis. These latter findings, together with the tendency for voluminous

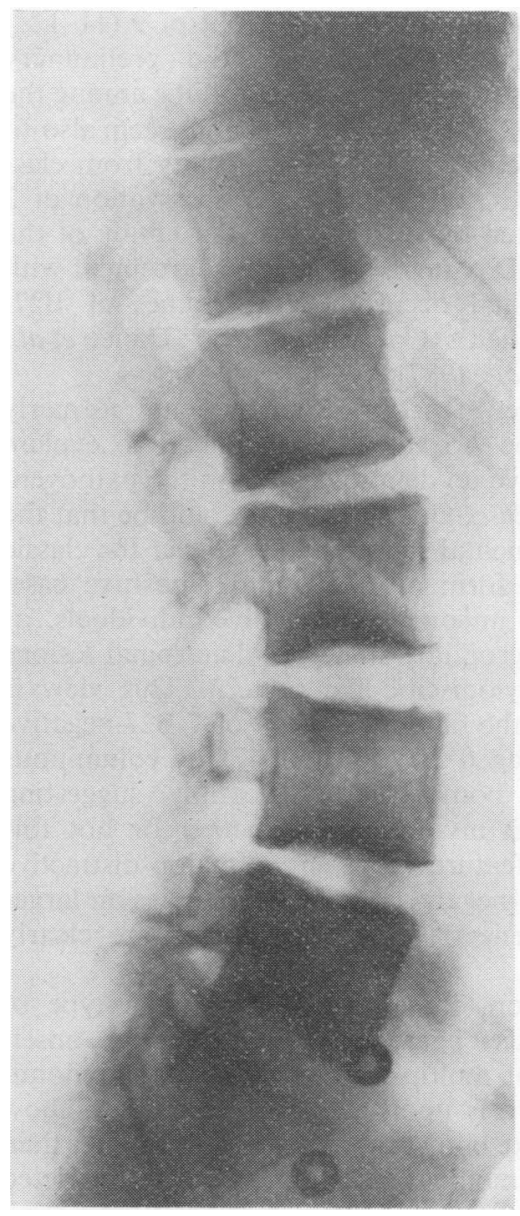

Fig. A case of multiple spondylodiscitis. Note the sclerosis of the adjacent vertebral plates with only minimal erosions.

intervertebral bony bridges to form, have suggested a different pathogenetic mechanism for this particular type of spondylodiscitis. The results obtained in this study seem to confirm these previous observations. In our 9 patients some clinical and radiological findings display peculiar features which distinguish them from classical AS (Table).

The main differences lie in the radiological aspect of the spine, which is characterised apart from SD, by the absence of typical syndesmophytosis and, eventually, by a precocious tendency to show voluminous oxteophytic-like bony bridges. These bony bridges recall those occurring in infectious spondylodiscitis.

A more striking difference is seen in the HLA typing which shows the absence in our 9 spondylodiscitic cases of the 'expected' increase of the B27 
antigen frequency; in fact only 1 out of $9(11 \cdot 1 \%)$ was B27-positive. Furthermore, the preliminary findings of no secondary AS or sacroiliitis among the relatives of $8 \mathrm{~B} 27$-negative AS probands seem also to indicate a different genetic susceptibility from classical AS. On the other hand, the observation of 2 brothers affected by sacroiliitis in the family of the B27-positive SD patient is in a good agreement with the high familial occurrence in families of B27positive AS patients (Contu et al., 1977; Daneo et al., 1977; Kidd et al., 1977).

The absence of B27 in our patients formerly included in the AS category is difficult to explain because we have no definitive data on the pathogenesis of the disease. One hypothesis could be that the same environmental stimuli which trigger the classic and complete form of AS in a B27-positive case, might develop in some B27-negative individuals, as well as the sacroiliitis, some peculiar spinal lesions with a spondylodiscitic-like pattern. This view is supported by the finding in 3 out of 7 B27-negative AS patients (aged 34, 38, and 47) of voluminous intervertebral bony bridges, possibly suggesting a previous SD involvement. Whether or not this peculiar SD feature represent a major distinctive marker in B27-negative AS, further studies on larger series of patients lacking B27 antigen are clearly needed.

In conclusion, these data show that a type of spondylodiscitis characterised by early onset, involvement of multiple vertebral bodies, predominance of sclerosis upon erosion, tendency to show osteophytic-like bony bridges at the spine rather than typical syndesmophytosis is almost solely restricted to B27-negative AS patients.

It seems possible that a different prevalence of this type of SD accounts partly for the reported deviation of the B27 positivity in some AS studies.

\section{References}

Cawley, M. I. D., Chalmers, T. M., Kellgren, J. H., and Ball, J. (1972). Destructive lesions of vertebral bodies in ankylosing spondylitis. Annals of the Rheumatic Diseases, 31, 345-358.

Contu, L., Capelli, P., and Sale, S. (1977). HLA B27 and ankylosing spondylitis: a population and family study in Sardinia. Journal of Rheumatology, 4, (Suppl. No. 3), 18-23.
Coste, F., Delbarre, F., Cayla, J., Massias, P., and Beaslay E. (1963). Spondylites destructives dans la spondylarthrite ankylosante. Presse médicale, 71, 1013-1016.

Daneo, V., and Di Vittorio, S. (1970). La spondylodiscite de la spondylarthrite ankylosante. Revue du Rhumatisme, 37 155-158.

Daneo, V., Migone, N., Modena, V., Bianchi, S. D., Alfier, G., Diotallevi, P., Carbonara, A. O., and Piazza, Ăㅡㅁ (1977). Family studies and HLA typing in ankylosing spondylitis and sacroiliitis. Journal of Rheumatology, (Suppl. No. 3), 5-10.

Doury, P., Delahaye, R.-P., Pattin, S., Metges, P.-J饱 Montely, J.-M., Wahl, D., Storch, H., and Salhi, A. (1975 La spondylodiscite pseudo-pottique au cours de la spondylarthrite ankylosante. Annales de Médecine interne, 126, 697-701.

Forestier, J., Jacqueline, F., and Rotès-Quérol, J. (1956 Ankylosing Spondylitis-Clinical Observations, Roen $\overline{6}$ genology, Pathological Anatomy and Treatment, trans. bo A. U. Desjardins. Thomas: Springfield, Illinois.

Gofton, J. P. (1968). Report from the subcommittee og diagnostic criteria for ankylosing spondylitis. In Population Studies of the Rheumatic Diseases, pp. 314-31\% ed. by P. H. Bennett and P. H. N., Wood. (Internationa Congress Series No. 148). Excerpta Medica Foundation.-

Gougeon, J., Rampon, S., Deshayes, P., Bussière, J.-L. Seignon, B., De Loet, X., Lopitaux, R., and Golenzer, (1977). Discopathies post-fracturaires et lésions vertébraleg destructrices au cours de la pelvispondylite rhumatismale Revue du Rhumatisme, 44, 17-25.

Jacqueline, F. (1956). Troubles de la structure osseuses lésions destructives au cours de la spondyloarthrite an losante. Journal de Radiologie, Electrologie et Médesine Nucleaire, 37, 887-891.

Kanefield, D. G., Mullins, B. P., Freehafer, A. A., Fufeg J. G., Horenstein, S., and Chamberlin, W. B. (1969 Destructive lesions of the spine in rheumatoid ankylosing spondylitis. Journal of Bone and Joint Surgery, 51 1369-1375.

Kidd, K. K., Bernoco, D., Carbonara, A. O., Daneo, V Steiger, U., and Ceppellini, R. (1977). Genetic analysis of HLA-associated diseases: the "illness susceptible" gene frequency and sex ratio in ankylosing spondylitis. II $H L A$ and Disease, pp. 72-80, ed. by J. Dausset and Svejgaard. Munksgaard: Copenhagen.

Little, H., Urowitz, M. B., Smithe, H. A., and Rosen, P. \$ (1974). Asymptomatic spondylodiscitis. An unusua्यु feature of ankylosing spondylitis. Arthritis and Rheumatisn 17, 487-493.

Rivelis, M., Freiberger, R. H. (1969). Vertebral destruction at unfused segments in late ankylosing spondylitis Radiology, 93, 251-256.

Romanus, R., and Ydén, S. (1952). Destructive and ossyfing changes in rheumatoid ankylosing spondylitis. Act Orthopedica Scandinavica, 22, 88-89.

Schulitz, K.-P. (1969). Spondylodiszitis bei Morbus Bech terew. Medizinische Klinik, 64, 593-597. 